\title{
Wnt Inhibitory Factor 1 (WIF1) Qualitative-Methylation from Peripheral Blood Could Not Be Used as Biomarker for The Risk of Nasopharyngeal Carcinoma or Smoking Behavior in Yogyakarta Panel
}

\author{
Aditya Kurniawan ${ }^{1}$, Erika Diana Risanti ${ }^{2}$, Saihas Suhda ${ }^{3}$, Hanggoro Tri Rinonce ${ }^{4}$, \\ Ery Kus Dwianingsih ${ }^{4}$, Jajah Fachiroh ${ }^{3, *}$ \\ ${ }^{1}$ Faculty of Medicine, Universitas Jember, Jl. Kalimantan 37, Jember, Indonesia \\ ${ }^{2}$ Faculty of Medicine, Muhammadiyah Universitas Surakarta, Jl. A. Yani, Pabelan, Surakarta, Indonesia \\ ${ }^{3}$ Department of Histology and Cell Biology, Faculty of Medicine, Public Health and Nursing, Universitas Gadjah Mada, Jl. Farmako Sekip Utara, \\ Yogyakarta, Indonesia \\ ${ }^{4}$ Department of Anatomical Pathology, Faculty of Medicine, Public Health and Nursing, Universitas Gadjah Mada, Jl. Farmako Sekip Utara, \\ Yogyakarta, Indonesia \\ *Corresponding author. E-mail: jajahfachiroh@ugm.ac.id
}

Received date: Apr 9, 2019; Revised date: Jun 18, 2019; Accepted date: Jul 16, 2019

\section{Abstract}

B ACKGROUND: Tobacco smoking plays an important role in nasopharyngeal carcinoma (NPC) risk. The Wingless-related integration site (WNT) Inhibitory Factor 1 (WIFl) as one of the tumor suppressor gene (TSG), functions to control cell proliferation through suppression of $W N T$ signaling pathway. WIF1 methylation is one of epigenetic mechanisms which causes overactivated of WNT pathway in NPC development. WIF1 methylation from buffy coat related to smoking status and NPC risk is not known yet.

METHODS: This was a nested case-control study involving 39 newly diagnosed NPC patients and 40 healthy controls. All subjects were enrolled at Dr. Sardjito Hospital, Yogyakarta. Subjects were male, with known smoking status, duration, and quantity of cigarette

\section{Introduction}

Nasopharyngeal carcinoma (NPC) is an epithelial cell malignancy located on the surface of the nasopharynx located after the nostrils and connects them to the throat. (1) The global NPC incidence is $1.7 / 100,000$ per year. The estimated incidence of NPC in Indonesia is $8.3 / 100,000$ consumed. Parallel DNA isolated from buffy coat was used for WIF1 DNA methylation analysis, by using methylation-specific PCR (MSP) method. Chi-square analysis was used to determine distribution of differences among groups. Two tailed $p$-value $\leq 0.05$ was considered as statistically significant.

RESULTS: No significant difference between WIFI methylation of cases and controls $(p=0.30)$, nor smoking habit among smokers $(p=0.51)$ and non-smokers $(p=0.43)$.

CONCLUSION: WIF1 methylation from buffy coat could not be used as an NPC marker nor as a smoking behavior marker.

KEYWORDS: buffy coat, cigarette smoking, methylation, nasopharyngeal carcinoma, WIF1

Indones Biomed J. 2019; 11(3): 273-8 per year, which makes it the fifth most common carcinoma among men in Indonesia. NPC is more common in men than in women with a ratio of 2.5:1.(2) Etiology of NPC is generally divided into three causes: Epstein-Barr virus (EBV) infection, carcinogenic exposure and genetic susceptibility. NPC will not occur if a person has only one factor, so there is no dominant factor of vulnerability. Carcinogenic exposures can be obtained from the 
environment. One of the most common carcinogenic exposures of the environment is cigarette smoking, which reported as NPC common risk in high and low incidence population.(3)

NPC has been reported to contain more methylation than mutations, when compared with other types of tumors.(4,5) Wingless-related integration site (WNT) Inhibitory Factor 1 (WIFl) is one of the DNA segments that frequently methylated and affected by cigarette smoking. It was reported that cigarette smoking increased the risk of WIF1 methylation by $88 \%$ in lung cancer.(6) WIF1 is one of the tumor suppressor genes (TSGs) that controls cell proliferation by suppressing $W N T$ gene expression (oncogene). WNT controls $\beta$-catenin expression. Overexpression of $\beta$-catenin leads to nasopharyngeal cancer progression.(7) WIF1 methylation was reported to be found in $61.2 \%$ of biopsies and brushing samples from NPC patients collected at Dr. Sardjito Hospital in Yogyakarta. (8) Until currently, there was no report that correlates WIF1 methylation, smoking behavior and nasopharyngeal carcinoma.

Tumor tissue is considered as the best source of information, due to tumor clonality. Particularly for NPC, the small size of tissue biopsy and the impact of preserving the tissue in formalin may limit the use of formalin-fixed paraffin embedded (FFPE) tissue for epigenetic studies. (9) The use of other type of samples such as nasopharynx brushings and peripheral blood for methylation studies were suggested as well due to the less invasiveness procedures. $(8,10)$

Previous report from our group showed that Ras Association Domain Family Member 1A (RASFF1A) and Cyclin Dependent Kinase Inhibitor 2A (CDKN2A) DNA methylation could be observed in buffy coat of NPC peripheral blood samples.(9) This was supported by an epigenome-wide association study (EWAS) of smoking conducted among twin and family, using DNA-derived peripheral blood collected as dried blood spots. The EWAS study revealed 39 CpGs differently methylated on never, former and current smokers.(11) These previous studies showed that DNA methylation could be detected from peripheral blood-derived DNA. $(9,11)$

Within this study, we discuss the detection of WIF1 methylation from buffy coat of peripheral blood, and further analysed its correlation with smoking behavior comparing NPC and healthy controls. Identification of WIF1 methylation in this study was conducted by using qualitative methylation-specific PCR (MSP) which broadly used to detect DNA methylation of known gene.

\section{Methods}

\section{Study Sample}

This was a nested case-control study, taken from the previous hospital-based case control study 2012-2014 at Dr. Sardjito General Hospital, Yogyakarta. Cases were those who newly diagnosed and histopathologically confirmed NPC. Healthy controls were those who declared healthy at the point of recruitment and never been diagnosed with any type of cancer. Data on clinical status, demographic, and smoking behavior including smoking status (smoker and not smoker), smoking duration and smoking quantity were collected in database. Peripheral blood samples, including separated buffycoat were collected from subjects and stored at $-80^{\circ} \mathrm{C}$ until used.

The inclusion criteria for this study was male, age conformity between case and control ( \pm 5 years) and had smoking status data (quantity and duration of smoking). Sample with poor quality and quantity of DNA were excluded. Further, this study could include 40 controls and 39 cases. Smoking status was determined as those who actively smoking until diagnosed, whole non smoker were those who never smoked regularly for at least a year.

The DNA used in this study were isolated from buffycoat, purified by using QIAamp DNA Blood Mini Kit (Qiagen, Hilden, Germany), and further, kept in $-20^{\circ} \mathrm{C}$ until used.

This study was approved by the Medical and Health Research Ethics Committee of the Faculty of Medicine, Public Health and Nursing, Universitas Gadjah Mada, Yogyakarta, Indonesia with reference number KE/FK/0078/ EC/2018.

\section{WIF1 Methylation Detection}

DNA underwent bisulfite modification using Cells-to$\mathrm{CpG}^{\mathrm{TM}}$ Bisulfite Conversion Kit (Applied Biosystem, California, USA). Modified DNA could be stored for a long time at $-20^{\circ} \mathrm{C}$. WIF1 methylation detection was analyzed using MSP methods, with methylation forward primer: 5'- CGT TTT ATT GGG CGT ATC GT -3', methylation reverse primer: 5' - ACT AAC GCG AAC GAA ATA CGA -3' (12); unmethylated forward primer: 5'- TTT TTG TTG TTT TTA TTT TTG TTT GT -3', and unmethylated reverse primer: 5'- TCC CAT TTA AAC AAC TAA ACA CA -3'.(13) MSP for methylation used Amplitaq Gold 360 (Thermofisher, California, USA). MSP for unmethylation used Invitrogen Platinum Taq Polymerase (Thermofisher). MSP process was conducted by using Applied Biosystems 
ProFlex PCR System (Thermofisher). Unmethylated and methylated WIF1 were observed in $2 \%$ agarose gel (in TAE buffer) with $148 \mathrm{bp}$ and $162 \mathrm{bp}$ DNA band, respectively.

\section{Statistical Analysis}

The proportions of methylation between case-control/ smoking status groups were observed using Chi-Square analysis. A two tailed $p$-value of $\leq 0.05$ was considered as statistically significant. Statistical analyses used IBM SPSS statistics v23.

\section{Results}

Characteristic of subjects are shown in Table 1. No difference was found between mean of age and smoking status between cases and controls $(p>0.05)$. The average duration of smoking and average cigarette consumption were also similar between cases and controls $(p>0.05)$.

Unmethylated and methylated WIF1 are shown as bands at $148 \mathrm{bp}$ and $162 \mathrm{bp}$, respectively (Figure 1). Differences of WIF1 methylation between cases and controls are shown in Table 2. Overall, WIF1 methylation was observed in 20 controls (50\%) and 15 cases (42.90\%) $(p=0.30)$ as shown in Table 2. Table 3 shows a comparison of WIF1 methylation between smokers and non-smokers, regardless of their NPC status. Overall, no significant difference was observed between both groups $(p=0.79)$

Stratified analysis of smoking behavior related to WIF1 methylation correlated with NPC risk is shown in
Table 4. Neither the smokers nor non-smokers group had significant differences in the WIF1 methylation status based on their NPC status. WIF1 methylation was detected among 7 (36.8\%) smoker NPC patients and 9 (47.4\%) smoker healthy people with Odds Ratio $(\mathrm{OR})=0.65$ and $p=0.51$. WIF1 methylation was detected among $8(40 \%)$ non-smoker NPC patients and $11(52.4 \%)$ non-smoker healthy people with $\mathrm{OR}=0.606$ and $p=0.43$.

\section{Discussion}

NPC is a malignancy reported to contain more DNA methylation than mutations, compared to other types of cancer. $(4,5)$ Similar to many cancers, tobacco smoking has been reported as a risk factor of NPC in low and high incidence populations. $(3,12)$ Methylation of WIF1 was reported to be highly detected in tissue of NPC $(8,13)$, while the association between methylation status of WIF 1 in peripheral blood and smoking behavior was reported only among lung cancer patients.(6)

The use of peripheral blood as an alternative to tumor tissues has been reported in different diseases, including cancers (14), diabetes (15) and cardiovascular disease (16). A study on colorectal cancer reported that methylation from whole blood could be used as a biological marker for diagnostic purpose. They reported that methylation of Aldehyde Oxidase 1 (AOX-1), Retinoic Acid Receptor-b2 (RARB2), Ras Like Estrogen Regulated Growth Inhibitor $(R E R G)$, Adam Metallopeptidase with Thrombospondin

Table 1. Subject characteristics.

\begin{tabular}{lccc}
\hline \multicolumn{1}{c}{ Variable } & $\begin{array}{c}\text { Control } \\
(\mathbf{n}=\mathbf{4 0})\end{array}$ & $\begin{array}{c}\text { Case } \\
(\mathbf{n}=\mathbf{3 9})\end{array}$ & $\boldsymbol{p}^{*}$ \\
\hline Age & & & \\
Mean \pm SD (year) & $49.58 \pm 2.56$ & $50.58 \pm 2.38$ & 0.79 \\
\hline $\begin{array}{l}\text { Smoking status } \\
\text { Smoker }\end{array}$ & 19 & 19 & 0.91 \\
$\quad$ Non-smoker & 21 & 20 & \\
\hline Smoking duration & & & \\
Mean \pm SD (year) & $28.89 \pm 13.07$ & $33.21 \pm 2.99$ & 0.47 \\
\hline Cigarette/day & & & \\
Mean \pm SD (year) & $8.95 \pm 1.30$ & $12.89 \pm 1.93$ & 0.21 \\
\hline WHO type & 0 & 1 & \\
Type 2 & 0 & 38 & \\
Type 3 & & & \\
\hline
\end{tabular}

*chi-square test; $p \leq 0.05$ considered as statistically different. 

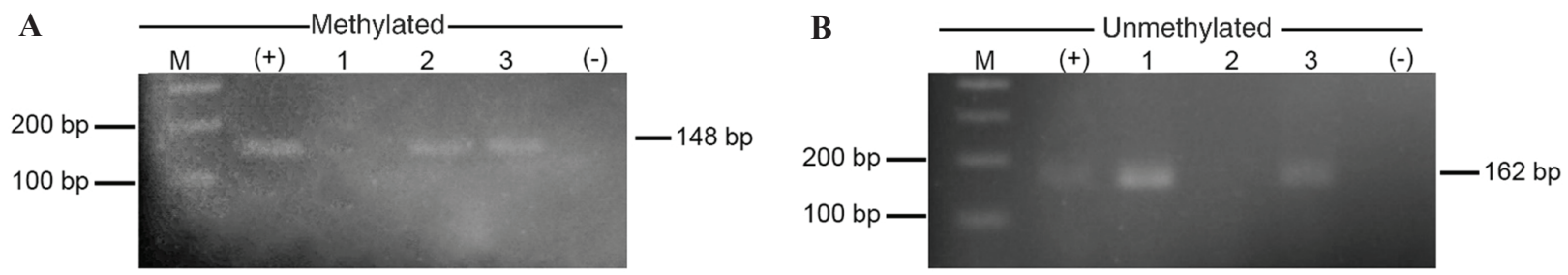

Figure 1. Methylation-specific PCR (MSP) result of WIF1 methylation detection. A: methylated-specific primer used for methylation detection; B: unmethylated-specific primer used for unmethylation detection. Sample 1 is unmethylation sample, sample 2 is methylated sample, and sample 3 is partially methylated sample and considered as methylated sample.

Type 1 Motif 9 (ADAMTS9), Interferon Regulatory Factor 4 (IRF4), and Forkhead Box E1 (FOXE-1) were higher among patients compared to healthy controls.(17) An EWAS in breast cancer, compared methylation of DNA from buffy coat of breast cancer patients and healthy people. The results showed that breast cancer patients had a higher number of methylated genes compared to healthy people. (18) Previous report from our group has shown that gene methylation could be detected in the buffycoat from NPC patient.(9) Further, both our studies may highlighted the capacity of buffy coat to be used in DNA methylation study. A study showed in the meta analysis, the superior detection of of RASFF 1A methylation for NPC diagnosis from NPC tissue compared to nasopharyngeal brushing and even less in peripheral blood.(10)

Within this study, in comparing NPC and control subjects, we did not find difference of WIF1 methylation status by using qualitative MSP. Therefore, in this study, WIF1 methylation status from buffy coat could not be used as a marker for the nasopharyngeal cancer. Previous study recommended a combination of five methylation marker including WIF1, RASSF1A, p16, Checkpoint with Forkhead and Ring Finger Domains (CHFR), and RetinoblastomaInteracting Zinc-Finger Protein 1 (RIZl) to predict NPC risk.(8) In the term of sampling invasiveness, buffy coat and nasopharynx brushings, known to be less invasive, could determine WIF1 methylation as well as biopsy sample by using multiplex MSP.(19) The WIF1 gene was found to be methylated in the nasopharyngeal cancer cell culture (C666-1). In this cell culture, WIF1, nemo like kinase $(N L K)$, and adenomatous polyposis coli (APC) genes were also methylated, resulting in the decreased expression of these three genes.(20) Other studies have shown that the methylation of WIF1, APC, O-6-Methylguanine-DNA Methyltransferase (MGMT) and RASSF12A genes from peripheral blood samples has a sensitivity of $86.5 \%$ and a specificity of $92.1 \%$ in detecting colorectal cancer.(21)

Cigarette smoke contains chemical compounds that contributes to carcinogenesis, e.g., arsenic, formaldehyde, aromatic amines, $\mathrm{N}$-nitrosamines, and volatile hydrocarbon. Those carcinogens damage DNA strains and recruited DNA repair proteins, one of which is DNA methyltransferase 1 (DNMT1), which causes DNA methylation.(22) Our study showed no difference on WIF1 methylation between non-

Table 2. WIF1 methylation status and NPC status.

\begin{tabular}{lccc}
\hline WIF1 Methylation Status & Control & Case & $\boldsymbol{p}^{*}$ \\
\hline Methylated & $20(50 \%)$ & $15(42.9 \%)$ & \\
Unmethylated & $20(50 \%)$ & $24(61.5 \%)$ & 0.3 \\
\hline
\end{tabular}

*chi-square test; $p \leq 0.05$ considered as statistically different.

Table 3. WIF1 methylation and smoking behavior.

\begin{tabular}{lccc}
\hline \multirow{2}{*}{ Smoking Status } & \multicolumn{2}{c}{ WIF1 Methylation Status } & \multirow{2}{*}{$\boldsymbol{p}$ * } \\
\cline { 2 - 3 } & Methylated & Unmethylated & \\
\hline Smoker & $16(45.7 \%)$ & $22(38.5 \%)$ & \multirow{2}{*}{0.79} \\
Non-smoker & $19(54.3 \%)$ & $22(61.5 \%)$ & \\
\hline
\end{tabular}

*chi-square test; $p \leq 0.05$ considered as statistically different. 
Table 4. Stratification analysis of WIF1 promoter gene methylation in case-control group of smoker and non-smoker subject.

\begin{tabular}{|c|c|c|c|c|c|c|c|c|}
\hline \multirow{2}{*}{ WIF1 Methylation Status } & \multicolumn{2}{|c|}{ Smoker } & \multirow{2}{*}{ OR } & \multirow{2}{*}{$p^{*}$} & \multicolumn{2}{|c|}{ Non-smoker } & \multirow{2}{*}{ OR } & \multirow{2}{*}{$p^{*}$} \\
\hline & Case & Control & & & Case & Control & & \\
\hline Unmethylated & $12(63.2 \%)$ & $10(52.6 \%)$ & \multirow{2}{*}{0.65} & \multirow{2}{*}{0.51} & $12(60 \%)$ & $10(47.6 \%)$ & \multirow{2}{*}{0.61} & \multirow{2}{*}{0.43} \\
\hline Methylated & $7(36.8 \%)$ & $9(47.4 \%)$ & & & $8(40 \%)$ & $11(52.4 \%)$ & & \\
\hline
\end{tabular}

*chi-square test; $p \leq 0.05$ considered as statistically different.

smokers and smokers, regardless of their NPC status. Study on non-small cell lung cancer (NSCLC) showed that WIF1 methylation correlated with bad prognosis instead of smoking habit. WIF1 methylation in NSCLC patients increased the risk of recurrence compared to unmethylated WIF1.(23) WIF1 methylation also correlated with smoking habit in Het-1A, an esophageal epithelial cell line. WIF1 expression became downregulated and correlated to methylation in Het-1A treated with mainstream smoke extract (MSA) and side-stream smoke extract (SSE) for 6 months.(24) Our prior study on RASSF1A and CDKN2A methylation status in peripheral blood showed no association with smoking behavior.(9) Similarly, in our study, WIF1 methylation of peripheral blood cell-derived DNA could not act as a smoking behavior marker. Regarding the suggested pattern by Lee and Pausova, correlation of smoking behavior and DNA methylation still needs to be observed in NPC by using other target genes in the TSG and oncogenes pathways.(22)

DNA methylation using qualitative approach might contributed to the result of the study, as it only assessed the presence and the absence of MSP product. Previous study showed that compared to bisulfite sequencing as gold standard for DNA methylation detection, qualitative MSP found less agreement than quantitative high resolution mass-spectrometry based approach (mass-ARRAY). This protocol yielded significant difference between high degree of Inhibitor of DNA Binding 4 (ID4) gene methylation of acute myeloid leukemia (AML) patients and low degree of ID4 gene methylation or unmethylation of healthy controls. (25) For further study, we propose the use of quantitative approach or at the minimum semi-quantitative assay such as high resolution melting (HRM), to further determine the role of smoking habit to the pathogenesis of NPC related to methylation of regulating genes.

Smoking behavior is one of many potential environmental factors that correlate with NPC. There are other environmental factors that may generate DNA methylation, such as diet, physical activity, drug consumption, and occupational exposure.(26,27) In future studies, it is suggested to do further analysis that discuss the association of methylation status quantitatively and potential environmental factors in a larger set of populations.

\section{Conclusion}

We concluded that WIF1 methylation was found in the blood cell-derived DNA. WIF1 methylation from the DNA buffy coat could not be used as either NPC nor smoking behavior markers.

\section{Acknowledgements}

We are grateful to the Ministry of Research, Technology and Higher Education of the Republic of Indonesia (DIKTI) for PUPT 2016 and Dana Masyarakat Universitas Gadjah Mada 2016 for grant funding. We also thank Sri Fatmawati and Sumartiningsih for technical assistance, as well as Dwi Hartati for taking care of the database.

\section{References}

1. Brennan B. Nasopharyngeal carcinoma. Orphanet J Rare Dis. 2006 1: 23. doi: 10.1186/1750-1172-1-23.

2. WHO [Internet]. Globocan 2012: Estimated Cancer Incidence Mortality and Prevalence Worldwide in 2012. World Health Organization. 2012 [cited 2018 Apr 5]. Available from: http:/ globocan.iarc.fr/Pages/fact_sheets_population.aspx.

3. Tsao SW, Yip YL, Tsang CM, Pang PS, Lau VMY, Zhang G, et al. Etiological factors of nasopharyngeal carcinoma. Oral Oncol. 2014; 50: 330-8.

4. Dai W, Cheung AKL, Ko JMY, Cheng Y, Zheng H, Ngan RKC, et al. Comparative methylome analysis in solid tumors reveals aberrant methylation at chromosome $6 \mathrm{p}$ in nasopharyngeal carcinoma. Cancer Med. 2015; 4: 1079-90.

5. Tsao SW, Tsang CM, Lo KW. 2017. Epstein-Barr virus infection and nasopharyngeal carcinoma. Philos Trans R Soc Lond B Biol Sci. 2017; 372: pii: 20160270. doi: 10.1098/rstb.2016.0270. 
6. Zheng Y, Li X, Jiang Y, Xu Y, Song B, Zhou Q, et al. Promoter hypermethylation of Wnt inhibitory factor-1 in patients with lung cancer. Medicine (Baltimore). 2016; 95: e5433.

7. Tulalamba W, Janvilisri T. Nasopharyngeal carcinoma signaling pathway: an update on molecular biomarkers. Int J Cell Biol. 2012; 2012: 594681. doi: 10.1155/2012/594681.

8. Hutajulu SH, Indrasari SR, Indrawati LP, Harijadi A, Duin S, Haryana $\mathrm{SM}$, et al. Epigenetic markers for early detection of nasopharyngeal carcinoma in a high risk population. Mol Cancer. 2011; 10: 48. doi: 10.1186/1476-4598-10-48

9. Risanti ED, Kurniawan A, Wahyuningsih L, Dwianingsih EK, Rinonce HT, Fachiroh J. Association of peripheral blood RASSF1A and CDKN2A methylation status with smoking behaviour in nasopharyngeal carcinoma. Indones Biomed J. 2018; 10: 123-7.

10. Ye M, Huang T, Ni C, Yang P, Chen S. Diagnostic capacity of RASFF1A promoter methylation as a biomarker in tissue, brushing, and blood samples of nasopharyngeal carcinoma. EBioMedicine. 2017; 18: 32-40

11. Li S, Wong EM, Bui M, Nguyen TL, Joo JHE, Stone J, et al. Causal effect of smoking on DNA methylation in peripheral blood: A twin and family study. Clin Epigenetics. 2018; 10: 1-12.

12. Xu FH, Xiong D, Xu YF, Cao SM, Xue WQ, Qin HD, et al. An epidemiological and molecular study of the relationship between smoking, risk of nasopharyngeal carcinoma, and Epstein-Barr Virus activation. J Natl Cancer Inst. 2012; 104: 1396-410.

13. Dai W, Zheng H, Cheung AKL, Lung ML. Genetic and epigenetic landscape of nasopharyngeal carcinoma. Chinese Clin Oncol. 2016; 5: 16 .

14. Li L, Choi JY, Lee KM, Sung H, Park SK, Oze I, et al. DNA methylation in peripheral blood: a potential biomarker for cancer molecular epidemiology. J Epidemiol. 2012; 22: 384-94.

15. Otterdijk SD Van, Binder AM, Szarc K, Schwald J, Michels KB. DNA methylation of candidate genes in peripheral blood from patients with type 2 diabetes or the metabolic syndrome. PLoS One. 2017; 12: e0180955. doi: 10.1371/journal.pone.0180955.

16. Nakatochi M, Ichihara S, Yamamoto K, Naruse K, Yokota S, Asano $\mathrm{H}$, et al. Epigenome-wide association of myocardial infarction with DNA methylation sites at loci related to cardiovascular disease. Clin Epigenetics. 2017; 9: 54. doi: 10.1186/s13148-017-0353-3.
17. Luo X, Huang R, Sun H, Liu Y, Bi H, Li J, et al. Methylation of a panel of genes in peripheral blood leukocytes is associated with colorectal cancer. Sci Rep. 2016; 6: 29922. doi: 10.1038/srep29922.

18. Severi G, Southey MC, English DR, Jung C, Lonie A, McLean C, et $a l$. Epigenome-wide methylation in DNA from peripheral blood as a marker of risk for breast cancer. Breast Cancer Res Treat. 2014; 148: 665-73.

19. Zhang Z, Sun D, Hutajulu SH, Nawaz I, Van DN, Huang G, et al. Development of a non-invasive method, multiplex methylation specific PCR (MMSP), for early diagnosis of nasopharyngeal carcinoma. PLoS ONE. 2011; 7: e45908. doi: 10.1371/journal. pone. 0045908 .

20. Zhao Z, Liu W, Liu J, Wang J, Luo B. The effect of EBV on WIF1, NLK, and APC gene methylation and expression in gastric carcinoma and nasopharyngeal cancer. J Med Virol. 2017; 89: 1844 51.

21. Lee BB, Lee EJ, Jung EH, Chun HK, Chang DK, Song SY, et al. Aberrant methylation of APC, MGMT, RASSF2A, and Wif-1 genes in plasma as a biomarker for early detection of colorectal cancer. Clin Cancer Res. 2009; 15: 6185-91.

22. Lee KWK, Pausova Z. Cigarette smoking and DNA methylation. Front Genet. 2013; 4: 132. doi: 10.3389/fgene.2013.00132.

23. Yoshino M, Suzuki M, Lei T, Yasumitsu M, Hidehisa H, Tatsuro O, et al. Promoter hypermethylation of the p16 and Wif- 1 genes as an independent prognostic marker in stage IA non-small cell lung cancers. Int J Oncol. 2009; 35: 4-11.

24. Huang Y, Chang X, Lee J, Cho YG, Zhong X, Park IS, et al. Cigarette smoke induces promoter methylation of single-stranded DNAbinding protein 2 in human esophageal squamous cell carcinoma. Int J Cancer. 2011; 128: 2261-73.

25. Claus R, Wilop S, Hielscher T, Sonnet M, Dahl E, Galm O, et al. A systematic comparison of quantitative high-resolution DNA methylation analysis and methylation-specific PCR. Epigenetics. 2012; 7: 772-80.

26. Lim U, Song M-A. Dietary and lifestyle factors of DNA methylation. In: Dumitrescu RG, Verma M, editors. Cancer Epigenetics: Methods and Protocols. Totowa, NJ: Humana Press; 2012. p.359-76.

27. Pacchierotti F, Spanò M. Environmental impact on DNA methylation in the germline: state of the art and gaps of knowledge. Biomed Res Int. 2015; 2015:123484. doi: 10.1155/2015/123484. 